\title{
Biocatalysed Concurrent Production of Enantioenriched Compounds through Parallel Interconnected Kinetic Asymmetric Transformations
}

\author{
Ana Rioz-Martínez, ${ }^{a}$ Fabricio Bisogno, ${ }^{a}$ Cristina Rodríguez, ${ }^{a}$ Gonzalo de Gonzalo, ${ }^{a}$ Iván Lavandera, ${ }^{a}$ \\ Daniel E. Torres Pazmiño, ${ }^{b}$ Marco W. Fraaije ${ }^{b}$ and Vicente Gotor*a
}

\author{
${ }_{5}$ Received (in $\left.X X X, X X X\right)$ Xth $X X X X X X X X X 200 X$, Accepted Xth XXXXXXXXX 200X \\ First published on the web Xth $X X X X X X X X X 200 X$ \\ DOI: $10.1039 / b 000000 x$
}

Parallel interconnected kinetic asymmetric transformations were performed in order to obtain enantioenriched derivatives starting from a set of racemic or prochiral compounds. Thus, in a one10 pot reaction using two redox biocatalysts (a BVMO and an $\mathrm{ADH}$ ) and a catalytic amount of cofactor that acts as a mediator, enantioenriched ketones, sulfoxides, and sec-alcohols were concurrently obtained in a strict parallel way minimising the quantity of reagents employed. By selecting the appropriate biocatalysts, this methodology is a potential tool for performing stereodivergent transformations.

\section{${ }_{15}$ Introduction}

Enantioenriched alcohols, ketones, and esters are important synthons in the pharmaceutical and (agro)chemical industry. ${ }^{1}$ To obtain them, several routes catalysed by (organo)metallic complexes have extensively been explored. ${ }^{2}$ Enantiopure 20 sulfoxides play an important role as chiral auxiliaries as well as in medicinal and pharmaceutical chemistry. ${ }^{3}$ Different methodologies have been described for the preparation of these derivatives as, for instance, the asymmetric oxidation of the corresponding prochiral sulfides. ${ }^{4}$

25 In the last few years, several biocatalytic processes using redox enzymes such alcohol dehydrogenases (ADHs) and Baeyer-Villiger monooxygenases (BVMOs) have been developed due to the high selectivities obtained employing mild and environmental friendly conditions. ${ }^{5}$ The synthesis of 30 chiral secondary alcohols via reduction of ketones or oxidative kinetic resolutions of rac-alcohols using ADHs have attracted attention. ${ }^{6}$ Additionally, BVMOs represent a very promising family of redox biocatalysts which are able to catalyse the oxidation of carbonyl compounds as well as 35 certain heteroatoms with excellent regio- and/or enantioselectivities. ${ }^{7}$ In despite of all the advantages provided by these enzymes, their implementation at industrial scale usually remains impeded due to the high costs related to the nicotinamide cofactor needed by these redox biocatalysts. 40 Therefore, various chemical, ${ }^{8,9}$ electrochemical, ${ }^{10}$ and enzymatic $^{11}$ methods have been explored in order to regenerate the coenzymes $\mathrm{NAD}(\mathrm{P}) \mathrm{H}$ or $\mathrm{NAD}(\mathrm{P})^{+}$. However, these methodologies have several drawbacks such as harmful effects on the biocatalyst, high costs and loss of material, 45 which diminishes the atom efficiency ${ }^{12}$ of the process.

In nature a huge number of chemically interconnected processes concurrently take place and the products are shared by different metabolic routes, forming a complex and effective metabolic network. ${ }^{13}$ For instance, redox trans50 formations share electron acceptors/donors such as $\mathrm{NAD}(\mathrm{P})^{+} / \mathrm{NAD}(\mathrm{P}) \mathrm{H}$ to connect oxidative and reductive reactions. In an attempt to mimic such efficient natural processes, concurrent catalytic concepts are being developed for the synthesis of enantioenriched derivatives. ${ }^{14}$ A nice ${ }_{55}$ example of this methodology was recently developed, ${ }^{15}$ by using three biocatalysts to simultaneously obtain morphinone and hydromorphone with a dehydrogenase and a reductase, respectively. The critical step was the employment of a transhydrogenase that permitted the internal cofactor60 recycling necessary to achieve each transformation (NADH and NADPH). Herein we describe a methodology which allows the concurrent preparation of enantioenriched derivatives in a strict parallel fashion, thereby minimising the quantity of reagents employed and maximising the redox ${ }_{65}$ economy $^{16}$ of the process by coupling two asymmetric transformations: a) via two kinetic resolutions or b) via a kinetic resolution and a desymmetrization reaction (Scheme 1). By a proper selection of both catalysts (an $\mathrm{ADH}$ and a BVMO) and using a catalytic amount of coenzyme (which 70 acts as connector) all possible enantiomers can be obtained in a one-pot process. $\mathrm{xxx}$

<Scheme 1 here>

Scheme 1. Obtaining of enantioenriched compounds by interconnecting two asymmetric processes.

\section{${ }_{75}$ Results and discussion}

When developing the system, several practical criteria were taken into consideration in advance. Since two different catalysts were used, parameters like $\mathrm{pH}$, temperature or cofactor preference must be optimised to find compatible reaction conditions. 80 Another criterion to take into account is that each substrate should be converted by only one of the biocatalysts, since an undesired side reaction would yield a by-product, and more importantly, an incomplete process as result of ineffective cofactor recycling (see below).

${ }_{85}$ As previously described, BVMOs catalyse irreversible oxidation processes at the expense of NADPH, ${ }^{17}$ while ADHs utilize $\mathrm{NAD}^{+}$and/or $\mathrm{NADP}^{+}$. As these biocatalysts require stoichiometric amounts of the expensive NAD $(\mathrm{P}) \mathrm{H}$ coenzyme, 
we designed a coupled process that involves a BVMOcatalysed oxidation and an ADH-catalysed oxidative kinetic resolution of a sec-alcohol, where the coenzyme will undergo internal recycling (Scheme 1a) ${ }^{18}$ Phenylacetone 5 monooxygenase (PAMO) ${ }^{19}$ from Thermobifida fusca, its M446G mutant ${ }^{20}$ and 4-hydroxyacetophenone monooxygenase $(\mathrm{HAPMO})^{21}$ from Pseudomonas fluorescens ACB were chosen as BVMOs due to their ability to catalyse enantioselective oxidations and to be readily obtainable in 10 recombinant form. ${ }^{22}$ We selected two ADHs with the same coenzyme preference $\left(\mathrm{NADP}^{+}\right)$and opposite stereopreference: alcohol dehydrogenases from Lactobacillus brevis $(\mathrm{LBADH})^{23}$ and from Thermoanaerobacter $\mathrm{sp}$. (ADH-T). ${ }^{24}$

Firstly, we studied the interconnected kinetic resolution of 15 ( \pm )-2-phenylpentan-3-one $\mathbf{1 a}^{22 \mathrm{c}}$ and $( \pm)$-2-octanol 3a with the BVMO-ADH couple by using equimolar amounts of both compounds and a catalytic amount of the nicotinamide cofactor (Scheme 2 and Table 1). Initial experiments performed with HAPMO and ADH-T (entries 1-6) showed 20 that the best reaction conditions were $20^{\circ} \mathrm{C}$ and $\mathrm{pH} 7.5$ (entry $1)$, yielding $(R)-\mathbf{1 a}$ and $(S)-\mathbf{2} \mathbf{a}^{25}$ in a highly selective process $(E \geq 200){ }^{26}$ When higher temperatures or $\mathrm{pHs}$ were used, lower conversions and selectivities were obtained, which is probably due to inactivation of HAPMO ${ }^{22 c}$ and ADH-T. It is 25 noteworthy that a catalytic amount of NADPH $(0.2 \mathrm{mM})$ was sufficient to achieve a successful process. Due to the fact that ADH-T is a Prelog ${ }^{27}$ enzyme, $(S)$-3a was selectively oxidised to $\mathbf{4 a}$, while remaining $(R)-\mathbf{3 a}$ was obtained with high $e e$. When HAPMO was combined with $\mathrm{LBADH}$ at $20^{\circ} \mathrm{C}$ and $\mathrm{pH}$ $308.5^{28}$ (entry 7), again an excellent double resolution was observed, although in this case alcohol $(S)$-3a was obtained. This shows that the selectivity of this system can simply be tuned by changing the employed biocatalysts.

Reactions were also carried out using PAMO as biocatalyst
35 (entries 8-16). As shown in entry 8 , when this enzyme was employed in combination with ADH-T, $(R)-\mathbf{1 a},(S)-\mathbf{2 a}$ and $(R)$-3a were achieved with conversions close to $50 \%$ in a process with excellent selectivity. The coupled system PAMO-LBADH was analysed in order to determine the best 40 reaction conditions. The effect of $\mathrm{pH}$ when conducting the oxidations with PAMO at $20^{\circ} \mathrm{C}$ was studied (entries 9-12), obtaining the best conditions for the resolution at $\mathrm{pH}$ 8.5-9.0. Higher $\mathrm{pHs}$ produced a loss in both activity and selectivity (entry 12). Once established $\mathrm{pH} 8.5$ as the optimum for this 45 system, the effect of the temperature was determined. Reactions could be performed at $30-40^{\circ} \mathrm{C}$ with excellent selectivities and good conversions (entries 13-14), while a further increase of the temperature at $50^{\circ} \mathrm{C}$ led to a loss in selectivity ( $E=29$, entry 15$)$ and finally an important decrease 50 in the activity at $60^{\circ} \mathrm{C}$ (entry 16). It is important to note that the system can even work at this high temperature. Surprisingly, in some cases traces of $n$-hexyl acetate derivative $\mathbf{5 a}$ were detected. ${ }^{29}$ This product is formed in a cascade process by the ADH-catalysed oxidation of $( \pm)-\mathbf{3 a}$ to ${ }_{55}$ 2-octanone $\mathbf{4 a}$ followed by its BVMO-catalysed oxidation (Scheme 2).

Concurrent catalysis is relatively demanding since all the steps should work at similar rates to ensure appropriate transformations. ${ }^{6 \mathrm{~b}}$ In this particular case, two asymmetric 60 transformations are truly occurring in a parallel way. If the reaction conditions are not appropriate, even for only one of the processes, both reactions will not be completed due to the fact that they are connected by a recycling agent (in this case the nicotinamide coenzyme) which is the key to the whole 65 system outcome. Considering the above mentioned features, this type of processes could be described as parallel interconnected kinetic asymmetric transformations. process. 
Table 1. Enzymatic kinetic resolution of racemic ketone 1a and ( \pm )-2-octanol 3a by using BVMOs and ADHs in a concurrent way. ${ }^{a}$

\begin{tabular}{|c|c|c|c|c|c|c|c|c|c|c|c|c|}
\hline Entry & BVMO & $\mathrm{ADH}$ & $\mathrm{pH}$ & $\mathrm{T}\left({ }^{\circ} \mathrm{C}\right)$ & $e e \mathbf{1 a}(\%)^{b}$ & $e e \mathbf{2} \mathbf{a}(\%)^{b}$ & $c(\%)^{\mathrm{c}}$ & $E^{d}$ & $e e \mathbf{3 a}(\%)^{b}$ & $\mathbf{3 a}(\%)^{b}$ & $4 \mathbf{a}(\%)^{b}$ & $5 \mathbf{a}(\%)^{b}$ \\
\hline 1 & HAPMO & $\mathrm{T}$ & 7.5 & 20 & 87 & 97 & 47 & $\geq 200$ & $53(R)$ & 46 & 51 & 4 \\
\hline 2 & HAPMO & $\mathrm{T}$ & 8.0 & 20 & 73 & 97 & 44 & 144 & $53(R)$ & 47 & 50 & 3 \\
\hline 3 & HAPMO & $\mathrm{T}$ & 8.5 & 20 & 57 & 97 & 37 & 102 & $58(R)$ & 38 & 60 & 2 \\
\hline 4 & HAPMO & $\mathrm{T}$ & 10 & 20 & 6 & 81 & 10 & 11 & $10(R)$ & 10 & 90 & -- \\
\hline 5 & HAPMO & $\mathrm{T}$ & 8.5 & 25 & 39 & 94 & 35 & 51 & $53(R)$ & 35 & 65 & -- \\
\hline 6 & HAPMO & $\mathrm{T}$ & 8.5 & 30 & 17 & 92 & 20 & 29 & $25(R)$ & 21 & 79 & -- \\
\hline 7 & HAPMO & LB & 8.5 & 20 & 92 & 98 & 48 & $\geq 200$ & $92(S)$ & 44 & 52 & 4 \\
\hline 8 & PAMO & $\mathrm{T}$ & 7.5 & 20 & 85 & 96 & 47 & 147 & $97(R)$ & 50 & 50 & -- \\
\hline 9 & PAMO & LB & 7.5 & 20 & 46 & 98 & 32 & 118 & $45(S)$ & 32 & 68 & -- \\
\hline 10 & PAMO & LB & 8.5 & 20 & 99 & 93 & 52 & 145 & $98(S)$ & 48 & 50 & 2 \\
\hline 11 & PAMO & LB & 9.0 & 20 & 91 & 96 & 49 & 156 & $98(S)$ & 50 & 50 & -- \\
\hline 12 & PAMO & LB & 10.0 & 20 & 40 & 97 & 29 & 66 & $41(S)$ & 30 & 70 & -- \\
\hline 13 & PAMO & LB & 8.5 & 30 & 90 & 97 & 48 & 160 & $98(S)$ & 50 & 50 & -- \\
\hline 14 & PAMO & LB & 8.5 & 40 & 70 & 96 & 42 & 106 & $61(S)$ & 38 & 62 & -- \\
\hline 15 & PAMO & LB & 8.5 & 50 & 50 & 89 & 36 & 29 & $64(S)$ & 39 & 59 & 2 \\
\hline 16 & PAMO & LB & 8.5 & 60 & 26 & 92 & 21 & 30 & $27(S)$ & 19 & 79 & 2 \\
\hline
\end{tabular}

${ }^{a}$ Reaction time: $24 \mathrm{~h}$. For other reaction details, see Experimental Section. ${ }^{b}$ Measured by GC. ${ }^{c}$ Conversion, $c=e e_{\mathrm{s}} /\left(e e_{\mathrm{s}}+e e_{\mathrm{p}}\right) .{ }^{d}$ Enantomeric ratio, $E=$ $\ln \left\{\left(1-e e_{\mathrm{s}}\right) /\left[1+\left(e e_{\mathrm{s}} / e e_{\mathrm{p}}\right)\right]\right\} / \ln \left\{\left(1+e e_{\mathrm{s}}\right) /\left[1+\left(e e_{\mathrm{s}} / e e_{\mathrm{p}}\right)\right]\right\}$.

${ }_{5}$ Once the best process conditions had been established at $\mathrm{pH}$ 8.5 and $20^{\circ} \mathrm{C}$, we studied the system with other substrates (Table 2). In a first set of experiments, ( \pm )-alcohol 3a was exchanged by using $( \pm)$-2-undecanol $\mathbf{3 b}$ or $( \pm)$-sulcatol $\mathbf{3 c}$ in combination with $( \pm)$-1a employing BVMOs and ADHs 10 (entries 1-8). It was observed that using ( \pm )-3b with PAMO (entries 3 and 4) yielded better conversions and enantioselectivities than with HAPMO (entries 1 and 2), and interestingly, also a smaller amount of ester 5b (n-nonyl acetate $)^{29}$ was produced. When alcohol $( \pm)-\mathbf{3 c}$ was used, the 15 resolution of $( \pm)$-1a was excellent, but depending on the ADH employed the obtained $e e$ for $\mathbf{3 c}$ varied. Thus, LBADH afforded enantiopure $(S)$-3c (entries 6 and 8) while ADH-T yielded the alcohol with low optical purity (entries 5 and 7). Control reactions incubating alcohols $( \pm)$-3a-c with ADH-T 20 and an excess of acetone showed that $\mathbf{3 a}$ and $\mathbf{3 b}$ were enantioselectively oxidised yielding the corresponding $(R)$ alcohols. On the other hand, $( \pm)$-sulcatol was oxidised with a conversion higher than $95 \%$, indicating that $\mathrm{ADH}-\mathrm{T}$ was not able to differentiate between both enantiomers of alcohol $\mathbf{3 c}$. 25 As described for ( \pm )-2-undecanol, a lower quantity of ester $5 \mathbf{c}^{28}$ was obtained when PAMO was used instead of HAPMO. Another ketone such as 4-phenylhexan-3-one ( \pm )-1b was also resolved in the presence of $( \pm)$-2-octanol 3a obtaining excellent enantioselectivities ( $E \geq 200$ in all cases) and high 30 ees for alcohol $\mathbf{3 a}^{25}$ (entries 9 to 12). For all the tested enzymes, only traces of $n$-hexyl acetate $\mathbf{5 a}$ were observed. To demonstrate the applicability of this system, this reaction was also performed at a 20 -fold larger scale obtaining enantiopure $(R)-\mathbf{1 b}$ and $(R)-3 \mathbf{a}$ with $50 \%$ conversion and good yields.

${ }_{35}$ Other experiments were carried out to demonstrate that both reactions must efficiently proceed to achieve an adequate system. Starting from an appropriate model, i.e. ( \pm )-1a and $( \pm)-3 \mathbf{a}$, one of these compounds was exchanged by a poor substrate for one of the enzymes. Thus, racemic 1a was 40 combined with 2-tetralol $( \pm)-3 d$ using ADH-T with the BVMOs. In both cases less than $3 \%$ of ester $2 \mathbf{a}$ was obtained after $24 \mathrm{~h}$. When ( \pm -1a was substituted by ( \pm - -2phenylheptan-3-one 1c in the reaction catalysed by PAMO and both ADHs in the presence of $( \pm)$-2-octanol, the Baeyer${ }_{45}$ Villiger oxidation of ketone $1 \mathrm{c}$ did not work (only $5 \%$ of ester 2c). However, the ADH-catalysed oxidation of $\mathbf{3 a}$ to $4 \mathbf{a}$ followed by cofactor regeneration provided by the BVMOcatalysed oxidation of $\mathbf{4 a}$ to $\mathbf{5 a}$, allowed the resolution of $( \pm)$ 3a obtaining $46 \%$ of enantiopure $(S)$-3a when LBADH was 50 employed. Furthermore, we observed the formation of ketone 4a $(6 \%)$ during production of 2c. When ADH-T was applied as biocatalyst, $8 \%$ of 2-octanone $\mathbf{4 a}$ (due to formation of $\mathbf{2 c}$ ) and $92 \%$ of $\mathbf{5 a}$ were obtained, since this ADH was able to oxidise both enantiomers of $\mathbf{3 a}$.

${ }_{55}$ In this approach, formation of final products ( 2 and 4 ) must be equal along the reaction course. If both resolutions exhibit similar enantioselectivities, remaining substrate ees (1 and 3), should be similar during the whole process. In order to verify this, we monitored the double kinetic resolution of $( \pm)-\mathbf{1 b}$ and $60( \pm)$-3a catalysed by PAMO and ADH-T (Figure 1). As can be seen, percentages of ester $\mathbf{2 b}$ and ketone $\mathbf{4 a}$ were nearly the same during the whole experiment. Furthermore, ee values of remaining $(R)$-1b and $(R)-\mathbf{3 a}$ remained similar. After 6 hours, $(R)-\mathbf{1 b}$ and 4a were slowly oxidised into the corresponding 65 esters.

\section{<Figure 1 here>}

Figure 1. Time study of the concurrent enzymatic resolution of $( \pm)-\mathbf{1 b}$ and ( \pm )-3a using PAMO and ADH-T. Percentage of: $\mathbf{2 b}(\bullet)$; $\mathbf{4 a}(\square)$; 5a $(\Delta)$; and enantiomeric excesses of: $(R)-\mathbf{1 b}(\mathbf{\bullet}) ;(R)-\mathbf{3 a}(\diamond)$ are represented. 
Table 2. Parallel interconnected kinetic resolutions of racemic ketones and $s e c$-alcohols by combining BVMOs and ADHs. ${ }^{a}$

\begin{tabular}{|c|c|c|c|c|c|c|c|c|c|c|c|c|c|}
\hline Entry & BVMO & $\mathrm{ADH}$ & ketone & alcohol & $\mathrm{t}(\mathrm{h})$ & ee $1(\%)^{b}$ & $e e \mathbf{2}(\%)^{b}$ & $c(\%)^{c}$ & $E^{d}$ & ee $\mathbf{3}(\%)^{b}$ & $3(\%)^{b}$ & $4(\%)^{b}$ & $5(\%)^{b}$ \\
\hline 1 & HAPMO & $\mathrm{T}$ & $( \pm)-1 a$ & $( \pm)-3 b$ & 24 & 66 & 97 & 48 & 144 & $73(R)$ & 35 & 57 & 8 \\
\hline 2 & HAPMO & LB & $( \pm)-1 a$ & $( \pm)-3 b$ & 24 & 52 & 97 & 46 & 114 & $66(S)$ & 33 & 59 & 8 \\
\hline 3 & PAMO & $\mathrm{T}$ & $( \pm)-1 a$ & $( \pm)-3 b$ & 24 & 64 & 96 & 46 & 145 & $87(R)$ & 48 & 52 & -- \\
\hline 4 & PAMO & LB & $( \pm)-1 a$ & $( \pm)-3 b$ & 24 & 99 & 89 & 53 & 132 & $99(S)$ & 49 & 50 & 1 \\
\hline 5 & HAPMO & $\mathrm{T}$ & $( \pm)-1 a$ & $( \pm)-3 c$ & 24 & 99 & 99 & 50 & $\geq 200$ & $3(R)$ & 38 & 50 & 12 \\
\hline 6 & HAPMO & LB & $( \pm)-1 a$ & $( \pm)-3 c$ & 24 & 99 & 95 & 51 & $\geq 200$ & $99(S)$ & 46 & 46 & 8 \\
\hline 7 & PAMO & $\mathrm{T}$ & $( \pm)-1 \mathbf{a}$ & $( \pm)-3 c$ & 24 & 93 & 96 & 48 & 179 & $21(R)$ & 48 & 50 & 2 \\
\hline 8 & PAMO & LB & $( \pm)-1 a$ & $( \pm)-3 c$ & 24 & 98 & 96 & 50 & $\geq 200$ & $99(S)$ & 48 & 50 & 2 \\
\hline 9 & HAPMO & $\mathrm{T}$ & $( \pm)-1 b$ & $( \pm)-3 a$ & 24 & 75 & 99 & 43 & $\geq 200$ & $76(R)$ & 41 & 57 & 2 \\
\hline 10 & HAPMO & LB & $( \pm)-1 b$ & $( \pm)-3 a$ & 24 & 87 & 99 & 47 & $\geq 200$ & $99(S)$ & 50 & 50 & -- \\
\hline 11 & PAMO & $\mathrm{T}$ & $( \pm)-1 b$ & $( \pm)-3 a$ & 6 & 99 & 96 & 50 & $\geq 200$ & $93(R)$ & 49 & 49 & 2 \\
\hline 12 & PAMO & LB & $( \pm)-1 b$ & $( \pm)-3 \mathbf{a}$ & 4.5 & 72 & 98 & 41 & $\geq 200$ & $71(S)$ & 42 & 58 & \\
\hline
\end{tabular}

${ }^{a}$ For reaction details, see Experimental Section. ${ }^{b}$ Measured by GC. ${ }^{c}$ Conversion, $c=e e_{\mathrm{s}} /\left(e e_{\mathrm{s}}+e e_{\mathrm{p}}\right) .{ }^{d}$ Enantomeric ratio, $E=$ $\ln \left\{\left(1-e e_{\mathrm{s}}\right) /\left[1+\left(e e_{\mathrm{s}} / e e_{\mathrm{p}}\right)\right]\right\} / \ln \left\{\left(1+e e_{\mathrm{s}}\right) /\left[1+\left(e e_{\mathrm{s}} / e e_{\mathrm{p}}\right)\right]\right\}$.

<Scheme 3 here>

Scheme 3. Stereodivergent concurrent preparation of sulfoxide $\mathbf{7}$ and $s e c$-alcohol $\mathbf{3}$ using this methodology $(\mathrm{t}=24 \mathrm{~h})$.

As BVMOs can catalyse the selective oxidation of different heteroatoms, we explored the stereodivergent and 10 simultaneous preparation of enantioenriched methyl phenyl sulfoxide (7) and alcohol 3a starting from prochiral thioanisole (6) and ( \pm )-3a (Schemes $1 \mathrm{~b}$ and 3 ). For this, we used either HAPMO, which selectively oxidised thioanisole to $(S)-7,{ }^{30}$ or mutant M446G PAMO, which is able to catalyse 15 the preparation of $(R)-7,{ }^{20}$ in combination with LBADH or ADH-T. As shown in Scheme 3, both compounds were achieved with excellent conversions and selectivities, and depending on the pair of catalysts employed we could obtain all possible stereoisomer pairs. Only small amounts of $n$-hexyl 20 acetate 5a were formed $(\leq 5 \%)$, and interestingly, no methyl phenyl sulfone was detected. Therefore, by simply tuning the biocatalysts employed, enantiocomplementary products could be easily obtained.

For a better understanding of the obtained ratios $\mathbf{2 a - b / 5 a - c}$ 25 and $\mathbf{5 a} / \mathbf{7}$, the steady-state kinetic parameters of BVMOs toward substrates 1a-b, $\mathbf{4 a - c}$ and $\mathbf{6}$ were determined. BVMOs clearly preferred racemic ketones $( \pm)-\mathbf{1 a}-\mathbf{b}$ and sulfide $\mathbf{6}$ when compared with compounds $\mathbf{4 a - c}$.

Table 3. Kinetic parameters for the Baeyer-Villiger oxidation of ketones $30( \pm)-\mathbf{1 a}-\mathbf{b},( \pm)-\mathbf{4 a - c}$ and sulfide $\mathbf{6}$.

\begin{tabular}{ccccc}
\hline Compound & BVMO & $K_{\mathrm{M}}(\mathrm{mM})$ & $k_{\text {cat }}\left(\mathrm{s}^{-1}\right)$ & $k_{\text {cat }} / K_{\mathrm{M}}\left(\mathrm{M}^{-1} \mathrm{~s}^{-1}\right)$ \\
\hline $\mathbf{( \pm ) - 1 a}$ & PAMO & 0.03 & 2.90 & 96,700 \\
$( \pm)-\mathbf{a}$ & HAPMO & 4.0 & 14.15 & 3,500 \\
$( \pm)-\mathbf{b}$ & PAMO & 0.02 & 2.54 & 127,000 \\
$( \pm)-\mathbf{b}$ & HAPMO & 0.10 & 4.06 & 40,600 \\
$( \pm)-4 a$ & PAMO & 0.23 & 0.39 & 1,700 \\
$( \pm)-4 a$ & HAPMO & 1.0 & 1.48 & 1,480 \\
$( \pm)-4 a$ & M446G & 1.34 & 0.25 & 190 \\
$( \pm)-4 b$ & PAMO & 0.07 & 0.37 & 5,300 \\
$( \pm)-4 b$ & HAPMO & 0.02 & 3.54 & 177,000 \\
$( \pm)-4 \mathbf{c}$ & PAMO & 2.5 & 1.70 & 680 \\
$( \pm)-4 \mathbf{c}$ & HAPMO & 1.3 & 0.39 & 300 \\
$\mathbf{6}$ & HAPMO & 0.36 & 3.02 & 8,400 \\
$\mathbf{6}$ & M446G & 1.00 & 0.90 & 900
\end{tabular}

As shown in Table 3, and in accordance with the interconnected system results, PAMO and HAPMO showed 35 different kinetic profiles. When comparing the data obtained with PAMO, it is interesting to note that $K_{\mathrm{M}}$ values display a relatively large variance, while $k_{\text {cat }}$ values for all substrates are in the same range. This observation was already noted in previous studies with this BVMO and suggested that the 40 maximal turnover rate did not depend on the chemical nature of the substrate. ${ }^{17,22 \mathrm{c}}$ On the contrary, a wide range of $k_{\text {cat }}$ (from 0.39 to $14.15 \mathrm{~s}^{-1}$ ) and $K_{\mathrm{M}}$ (from 0.02 to $4.0 \mathrm{mM}$ ) values were observed with HAPMO. These enzymes (in particular HAPMO) showed an acceptable catalytic efficiency towards 45 aliphatic ketones $4 \mathbf{a}-\mathbf{c}$, which explains the amount of acetates 5 obtained in these reactions. Despite the high catalytic efficiency, 2-undecanone $\mathbf{4 b}$ showed inhibition of HAPMO activity at high substrate concentrations (>5 mM). Interestingly, although the catalytic efficiencies of both 50 processes are rather different (the Baeyer-Villiger oxidation appeared as the rate limiting step), the transformations occur in a strict parallel fashion due to the $\mathrm{NADP}^{+} / \mathrm{NADPH}$ loop. Thus, the Baeyer-Villiger oxidation is the rate limiting step in our system considering the high catalytic efficiency of ADHs 55 with the selected alcohols. In case of LBADH, 2-octanol was oxidised in $50 \mathrm{mM}$ Tris- $\mathrm{HCl}$ buffer $\mathrm{pH} 8.5$ at $41 \mathrm{~s}^{-1}$ and showed a $K_{\mathrm{M}}$ value of $0.29 \mathrm{mM}$.

\section{Conclusions}

In this report we describe an integrated coenzyme 60 regeneration cycle which allows parallel interconnected kinetic asymmetric transformations. By using this methodology, we could simultaneously obtain enantiopure compounds (via kinetic resolution or desymmetrization) and minimise the quantity of reagents employed. The reported 65 one-pot reactions are performed using two biocatalysts and a catalytic amount of nicotinamide cofactor which is internally recycled and acts as a connector between both processes. They 
strictly occur in parallel and at least one of the transformations must be (quasi)irreversible to ensure good results. In addition, the selectivity of this system can simply be tuned by changing the employed biocatalysts. As a 5 consequence, the selection of catalysts, connector, and substrates must be carefully taken into account.

We have shown that the kinetic properties of the biocatalysts support the obtained experimental results. Both BVMOs prefer aromatic compounds $( \pm)$-1a and $( \pm)$-1b over aliphatic

10 ketones 4a-c. Interestingly, the oxidation of these latter compounds by BVMOs is also possible, opening new possibilities in order to oxidise such derivatives. We have demonstrated that this procedure is not only feasible with enantioselective Baeyer-Villiger oxidations but also with 15 asymmetric sulfoxidations. This system shows the possibility of controlling biocatalytic processes in parallel with a defined purpose as occurs in nature.

\section{Experimental}

PAMO, its M446G mutant and HAPMO were overexpressed 20 and purified according to previously described methods. ${ }^{19-21}$ The oxidation reactions were performed using purified enzymes or cell free extract preparations of the corresponding overexpressed enzyme. One unit (U) of Baeyer-Villiger monooxygenase (BVMO) oxidises $1.0 \mu \mathrm{mol}$ of 2${ }_{25}$ phenylpentan-3-one 1a to 1-phenylethyl propionate $\mathbf{2 a}$ per minute at $\mathrm{pH} 8.0$ and $20^{\circ} \mathrm{C}$ in the presence of NADPH. Alcohol dehydrogenases from Lactobacillus brevis $\mathrm{ADH}$ (LBADH) and Thermoanaerobacter sp. ADH (ADH-T) were purchased from commercial sources. The amount of ADH 30 used in the different assays was calculated according to the activity data provided by the supplier (ADH-T $780 \mathrm{U} \mathrm{mL}^{-1}$, LBADH 2,320 $\mathrm{U} \mathrm{mL}^{-1}$ ). Racemic alcohols ( \pm )-3a-3d, ketones 4a-4d, methyl phenyl sulfide (6), racemic phenyl methyl sulfoxide [( \pm -7] as well as other reagents and solvents were 35 of the highest quality grade available, supplied by SigmaAldrich-Fluka. Racemic compounds $( \pm)-\mathbf{1 a - 1 c}$ were prepared according to the literature. ${ }^{31}$ Racemic esters $( \pm)-2 \mathbf{a}-2 \mathbf{c}$ were synthesised by acylation of commercial 1-phenylethanol or 1phenylpropanol using propionic or valeric anhydride (yields 40 higher than $80 \%$ ). Compounds 5a-5c were prepared by conventional acetylation of the corresponding primary alcohols using acetic anhydride and DMAP.

Flash chromatography was performed using Merck silica gel 60 (230-400 mesh). IR spectra were recorded on a Perkin-

${ }_{45}$ Elmer 1720-X infrared Fourier transform spectrophotometer using $\mathrm{KBr}$ pellets. ${ }^{1} \mathrm{H} \mathrm{NMR},{ }^{13} \mathrm{C}$ NMR and DEPT spectra were recorded with TMS (tetramethylsilane) as the internal standard with a Bruker AC-300-DPX $\left({ }^{1} \mathrm{H}, 300.13 \mathrm{MHz}\right.$ and $\left.{ }^{13} \mathrm{C}, 75.4 \mathrm{MHz}\right)$ spectrometer. The chemical shift values $(\delta)$ 50 are given in ppm and the coupling constants $(J)$ in $\operatorname{Hertz}(\mathrm{Hz})$. For $\mathrm{ESI}^{+}$, a HP 1100 chromatograph mass detector and for $\mathrm{EI}^{+}$ a Finigan MAT 95 spectrometer were used to record mass spectra (MS). GC analyses were performed on a Hewlett Packard 6890 Series II chromatograph. HPLC analyses were 55 developed with a Hewlett Packard 1100 LC liquid chromatograph.
General procedure for the enzymatic resolution of racemic ketones and alcohols catalysed by BVMOs and ADHs

Racemic ketones $( \pm)-\mathbf{1 a}-\mathbf{b}(10-15 \mathrm{mM})$ were dissolved in a ${ }_{60}$ Tris- $\mathrm{HCl}$ buffer (50 mM, different $\left.\mathrm{pHs}, 0.5 \mathrm{~mL}\right)$. Then, NADPH $(0.2 \mathrm{mM})$, the corresponding ADH (2 U), HAPMO or PAMO ( $2 \mathrm{U})$, and racemic alcohols $( \pm)$-3a-c (1 equiv.) were added. When LBADH was used, magnesium chloride (final concentration, $1 \mathrm{mM}$ ) was added to the reaction medium. The 65 mixture was shaken at $250 \mathrm{rpm}$ at selected temperatures. The reaction was stopped by extraction with ethyl acetate $(2 \times 0.5$ $\mathrm{mL}$ ) and the organic layer was dried over $\mathrm{Na}_{2} \mathrm{SO}_{4}$. Conversions and enantiomeric excesses of compounds $\mathbf{1 a - b}$, 2a-b, 3a-c, 4a-c, and 5a-c were determined by GC analysis.

\section{Reaction of ketone ( \pm )-1a and alcohol ( \pm )-3a using PAMO and ADH-T as biocatalysts at multimilligram scale}

Ketone 1a (25 mg, $11.3 \mathrm{mM}$ ) was dissolved in a Tris- $\mathrm{HCl}$ buffer (50 mM, pH 7.5, $12.5 \mathrm{~mL})$. Then, NADPH (0.2 mM), ADH-T (20 U), PAMO (20 U), and racemic alcohol 3a (22.5 $75 \mu \mathrm{L}, 11.3 \mathrm{mM})$ were added. The mixture was shaken at $20^{\circ} \mathrm{C}$ and $250 \mathrm{rpm}$ for $6 \mathrm{~h}$. Then, the reaction was stopped by extraction with ethyl acetate $(5 \times 5 \mathrm{~mL})$ and the organic layer was dried over $\mathrm{Na}_{2} \mathrm{SO}_{4}$. Afterwards, the organic solvents and remanent ketone $\mathbf{4 a}$ were removed under reduced pressure and 80 the crude residue was purified using flash chromatography (hexane: $\left.\mathrm{CH}_{2} \mathrm{Cl}_{2} 1: 1\right)$ obtaining enantiopure $(R)-\mathbf{1 a}(10.1 \mathrm{mg}$, $81 \%$ yield), $(S)-\mathbf{2 a}(11.7 \mathrm{mg}, 86 \%$ yield), and $(R)-\mathbf{3 a}(7.0 \mathrm{mg}$, $75 \%$ yield). Chemical purity of reaction products was determined by both GC and NMR.

\section{${ }_{85}$ General procedure for the oxidation of thioanisole and ( \pm )-2- octanol catalysed by BVMOs and ADHs}

Sulfide 6 (14.5 mM) was added to Tris-HCl buffer $(50 \mathrm{mM}$, $\mathrm{pH} 7.5,0.5 \mathrm{~mL})$ containing $1 \% \mathrm{v} \mathrm{v}^{-1}$ DMSO. Then, NADPH $(0.2 \mathrm{mM})$, the corresponding ADH (2 U), HAPMO (2 U), and 90 racemic alcohol 3a $(30 \mathrm{mM})$ were added. When $\mathrm{LBADH}$ was used, magnesium chloride ( $1 \mathrm{mM}$, final concentration) was added to the reaction medium. The mixture was shaken at $30^{\circ} \mathrm{C}$ and $250 \mathrm{rpm}$ for $24 \mathrm{~h}$. Then, the reactions were stopped by extraction with ethyl acetate $(2 \times 0.5 \mathrm{~mL})$ and the organic 95 layer was dried over $\mathrm{Na}_{2} \mathrm{SO}_{4}$. Conversions and enantiomeric excesses of final compounds were determined by GC and HPLC analysis.

HAPMO-catalysed sulfoxidation of thioanisole (6) coupled 100 with the kinetic resolution of $( \pm)$-2-octanol (3a) catalysed by LBADH

Sulfide 6 (20 mg, $23 \mathrm{mM}$ ) was added into a preparation of cell free extract (in Tris- $\mathrm{HCl}$ buffer $50 \mathrm{mM} \mathrm{pH} \mathrm{7.5)} \mathrm{from}$ recombinant $E$. coli TOP10 overexpressing HAPMO $(7 \mathrm{~mL}$, 105 with a total protein concentration of approx. $10 \mathrm{mg} \mathrm{mL}$ containing $1 \% \mathrm{v} \mathrm{v}^{-1}$ DMSO). Then, NADPH (0.2 mM), $\mathrm{MgCl}_{2}$ (1 mM), LBADH (20 U), and racemic 2-octanol 3a $(54 \mu \mathrm{L}, 47$ $\mathrm{mM})$ were added. The mixture was shaken at $20^{\circ} \mathrm{C}$ and 250 rpm for $24 \mathrm{~h}$. Then, the reaction was stopped by extraction 110 with diethyl ether $(5 \times 5 \mathrm{~mL})$ and the organic layer was dried over $\mathrm{Na}_{2} \mathrm{SO}_{4}$. Afterwards, the organic solvents were carefully removed under reduced pressure at low temperature and the 
crude residue was purified using flash chromatography (hexane: $\mathrm{CH}_{2} \mathrm{Cl}_{2}$ mixtures of increasing polarities) obtaining enantiopure $(S)-7$ (18.5 mg, 84\% isolated yield) and $(S)$-3a (20 $\mu \mathrm{L}, 74 \%$ isolated yield). Chemical purity of reaction 5 products was determined by both GC and NMR.

\section{Acknowledgments}

A.R.-M. (FPU program) thanks the Spanish Ministerio de Ciencia e Innovación (MICINN) for her predoctoral fellowship which is financed by the European Social Fund. ${ }_{10}$ F.R.B. is supported by the Programme Alßan, the European Union Program of High Level Scholarships for Latin America (scholarship No. E07D402519AR). C.R. thanks the Principado de Asturias for her predoctoral fellowship. G.d.G. (Juan de la Cierva Program) thanks MICINN for personal funding. I.L. 15 thanks the Principado de Asturias for personal funding (Clarín Program). Financial support from MICINN (Project CTQ2007-61126) is gratefully acknowledged. M.W.F. and D.E.T.P. receive support from the EU-FP7 "Oxygreen" project.

\section{${ }_{20}$ Notes and references}

a Departamento de Química Orgánica e Inorgánica, Instituto Universitario de Biotecnología de Asturias, Universidad de Oviedo, C/ Julián Clavería 8, 33006 Oviedo, Spain. Fax: (+) 34985 103448; Tel: (+) 34985 103448; E-mail: vgs@fq.uniovi.es

$25^{b}$ Laboratory of Biochemistry, Groningen Biomolecular Sciences and Biotechnology Institute, University of Groningen, Nijenborgh 4, 9747 AG Groningen, The Netherlands.

$\dagger$ Electronic Supplementary Information (ESI) available: [experimental procedures, kinetic data and analytics can be found]. See 30 DOI: $10.1039 / \mathrm{b} 000000 \mathrm{x} /$

1 M. Breuer, K. Ditrich, T. Habicher, B. Hauer, R. Stürmer and T. Zelinski, Angew. Chem. Int. Ed., 2004, 43, 788.

2 Some recent examples: a) J. Piera and J.-E. Bäckvall, Angew. Chem. Int. Ed., 2008, 47, 3506; b) X. Wu and J. Xiao, Chem. Commun., 2007, 2449; c) T. Ikariya and A. J. Blacker, Acc. Chem. Res., 2007, 40, 1300; d) M. T. Reetz and X. Li, J. Am. Chem. Soc., 2006, 128, 1044; e) G.-J. ten Brink, I. W. C. E. Arends and R. A. Sheldon, Chem. Rev., 2004, 104, 4105.

3 For some reviews, see: a) M. C. Carreño, G. Hernández-Torres, M. 40 Ribagorda and A. Urbano, Chem. Commun., 2009, 6129; b) H. Pellissier, Tetrahedron, 2006, 62, 5559; b) R. Bentley, Chem. Soc. Rev., 2005, 34, 609.

4 a) J. Legros, J. R. Dehli and C. Bolm, Adv. Synth. Catal., 2005, 347, 19; b) I. Fernández and N. Khiar, Chem. Rev., 2003, 103, 3651; c) H. L. Holland, Nat. Prod. Rep., 2001, 18, 171.

5 Modern Biooxidation. Enzymes, Reactions and Applications, R. D. Schmid and V. B. Urlacher, Eds.; Wiley-VCH, Weinheim, 2007.

6 Recent bibliography: a) S. Buchholz and H. Gröger in Biocatalysis in the Pharmaceutical and Biotechnology Industry, R. N. Patel, Ed.;

$50 \quad$ CRC Press, Boca Raton, 2007, p 757; b) S. M. A. de Wildeman, T. Sonke, H. E. Schoemaker and O. May, Acc. Chem. Res., 2007, 40, 1260; c) J. C. Moore, D. J. Pollard, B. Kosjek and P. N. Devine, Acc. Chem. Res., 2007, 40, 1412; d) K. Goldberg, K. Schroer, S. Lütz and A. Liese, Appl. Microbiol. Biotechnol., 2007, 76, 237; e) W. Kroutil,

55 H. Mang, K. Edegger and K. Faber, Curr. Opin. Chem. Biol., 2004, $\mathbf{8}, 120$.

7 a) M. M. Kayser, Tetrahedron, 2009, 65, 947; b) D. E. Torres Pazmiño and M. W. Fraaije in Future Directions in Biocatalysis, T. Matsuda, Ed.; Elsevier, Dordrecht, 2007, p 107; c) M. W. Fraaije and

60 D. B. Janssen in Modern Biooxidation, R. D. Schmid and V. B. Urlacher, Eds.; Wiley-VCH, Weinheim, 2007, p 77; d) M. D. Mihovilovic, Curr. Org. Chem., 2006, 10, 1265; e) N. M.
Kamerbeek, D. B. Janssen, J. H. Van Berkel and M. W. Fraaije, Adv. Synth. Catal,. 2003, 345, 667.

658 Employing metal catalytsts: a) F. Hollmann, K. Hofstetter and A Schmid, Trends Biotechnol., 2006, 24, 163; b) G. de Gonzalo, G. Ottolina, G. Carrea and M. W. Fraaije, Chem. Commun., 2005, 3724; c) F. Hollmann, P.-C. Lin, B. Witholt and A. Schmid, J. Am. Chem. Soc., 2003, 125, 8209.

709 Recent examples employing an excess of an alcohol/ketone as hydrogen donor/acceptor: a) M. Kurina-Sanz, F. R. Bisogno, I. Lavandera, A. A. Orden and V. Gotor, Adv. Synth. Catal., 2009, 351, 1842; b) M. J. Sorgedrager, F. van Rantwijk, G. W. Huisman and R. A. Sheldon, Adv. Synth. Catal., 2008, 350, 2322; c) I. Lavandera, A.

75 Kern, V. Resch, B. Ferreira-Silva, A. Glieder, W. M. F. Fabian, S. de Wildeman and W. Kroutil, Org. Lett., 2008, 10, 2155; d) S. Dreyer and U. Kragl, Biotechnol. Bioeng., 2008, 99, 1416; e) M. M. Musa, K. I. Ziegelmann-Fjeld, C. Vieille, J. G. Zeikus and R. S. Phillips, Angew. Chem. Int. Ed., 2007, 46, 3091; f) G. de Gonzalo, I. $80 \quad$ Lavandera, K. Faber and W. Kroutil, Org. Lett., 2007, 9, 2163; g) M. M. Musa, K. I. Ziegelmann-Fjeld, C. Vieille, J. G. Zeikus and R. S. Phillips, J. Org. Chem., 2007, 72, 30.

10 a) E. Siu, K. Won and C. B. Park, Biotechnol. Prog., 2007, 23, 293 ; b) R. Ruinatscha, V. Höllrigl, K. Otto and A. Schmid, Adv. Synth. 85 Catal., 2006, 348, 2015; c) F. Hollmann, K. Hofstetter, T. Habicher, B. Hauer and A. Schmid, J. Am. Chem. Soc., 2005, 127, 6540.

11 Recent examples: a) H. Gröger, C. Rollmann, F. Chamouleau, I. Sebastien, O. May, W. Wienand and K. Drauz, Adv. Synth. Catal., 2007, 349, 709; b) H. Gröger, F. Chamouleau, N. Orologas, C.

90 Rollmann, K. Drauz, W. Hummel, A. Weckbecker and O. May, Angew. Chem. Int. Ed., 2006, 45, 5677; c) J. Zhang, B. Witholt and Z. Li, Adv. Synth. Catal., 2006, 348, 429; d) A. S. Bommarius, M. Schwarm and K. Drauz, J. Mol. Catal. B: Enzym., 1998, 5, 1.

12 a) R. A. Sheldon, Pure Appl. Chem., 2000, 72, 1233; b) B. M. Trost, Science, 1991, 254, 1471.

13 D. L. Nelson and M. M. Cox, Lehninger Principles of Biochemistry, W. H. Freeman \& Co., New York, 2004.

14 a) F. R. Bisogno, I. Lavandera, W. Kroutil and V. Gotor, J. Org. Chem., 2009, 74, 1730; b) C. V. Voss, C. C. Gruber and W. Kroutil, Angew. Chem. Int. Ed., 2008, 47, 741.

15 B. Boonstra, D. A. Rathbone, C. E. French, E. H. Walker and N. C. Bruce, Appl. Environ. Microbiol. 2000, 66, 5161.

16 N. Z. Burns, P. S. Baran and R. W. Hoffmann, Angew. Chem. Int. Ed., 2009, 48, 2854.

10517 D. E. Torres Pazmiño, B.-J. Baas, D. B. Janssen and M. W. Fraaije, Biochemistry, 2008, 47, 4082.

18 There are only few examples where a BVMO and an ADH were combined. Thus, Zambianchi et al. used CHMO and ADH from Thermoanaerobium brockii with an excess of 2-propanol to recycle 110 the cofactor: F. Zambianchi, P. Pasta, G. Carrea, S. Colonna, N. Gaggero and J. M. Woodley, Biotechnol. Bioeng., 2002, 78, 488. Willetts et al. used Acinetobacter calcoaceticus monooxygenase with the previous ADH to oxidise bicyclic ketones in a cascade process: A. J. Willetts, C. J. Knowles, M. S. Levitt, S. M. Roberts, H. Sandey and N. F. Shipston, J. Chem. Soc., Perkin Trans. 1, 1991, 1608.

19 M. W. Fraaije, J. Wu, D. P. H. M. Heuts, E. W. van Hellemond, J. H. Lutje Spelberg and D. B. Janssen, Appl. Microbiol. Biotechnol., 2005, 66, 393.

20 D. E. Torres Pazmiño, R. Snajdrova, D. V. Rial, M. D. Mihovilovic 120 and M. W. Fraaije, Adv. Synth. Catal., 2007, 349, 1361.

21 a) N. M. Kamerbeek, A. J. J. Olsthoorn, M. W. Fraaije and D. B. Janssen, Appl. Environ. Microbiol., 2003, 419.

22 a) D. E. Torres Pazmiño, R. Snajdrova, B.-J. Baas, M. Ghobrial, M. D. Mihovilovic and M. W. Fraaije, Angew. Chem. Int. Ed., 2008, 47,

1252275 ; b) C. Rodríguez, G. de Gonzalo, M. W. Fraaije and V. Gotor, Tetrahedron: Asymmetry, 2007, 18, 1338; c) G. de Gonzalo, D. E. Torres Pazmiño, G. Ottolina, M. W. Fraaije and G. Carrea, Tetrahedron: Asymmetry, 2005, 16, 3077; d) D.E. Torres Pazmiño, A. Riebel, J. de Lange, F. Rudroff, M.D. Mihovilovic, M.W. Fraaije, ChemBioChem, 2009, 10, 2595-2598.

23 M. Wolberg, W. Hummel, C. Wandrey and M. Müller, Angew. Chem. Int. Ed., 2000, 39, 4306. 
24 Z. Findrik, D. Vasić-Racki, S. Lütz, T. Daussmann and C. Wandrey, Biotechnol. Lett., 2005, 27, 1087.

25 Absolute configurations were asigned as shown in reference $21 \mathrm{~b}$.

$26 E$ (enantiomeric ratio) is an adequate parameter to quantify the

5 selectivity of the biocatalysed kinetic resolutions. See: C.-S. Chen, Y. Fujimoto, G. Girdauskas and C. J. Sih, J. Am. Chem. Soc., 1982, 104, 7295.

27 V. Prelog, Pure Appl. Chem., 1964, 9, 119.

28 In contrast to ADH-T, using $\mathrm{LBADH}$ we observed that working at $\mathrm{pH} 8.5$ excellent results were already obtained.

29 These compounds were independently synthesised and their formation in the experiments was corroborated by GC injection

30 G. de Gonzalo, D. E. Torres Pazmiño, G. Ottolina, M. W. Fraaije and G. Carrea, Tetrahedron: Asymmetry, 2006, 17, 130

1531 A. J. Fry and J. P. Bujanauskas, J. Org. Chem., 1978, 43, 3157. 